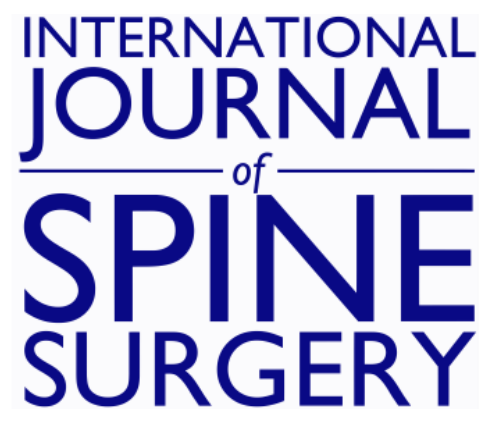

\title{
Interlaminar Endoscopic Lumbar Discectomy: A Narrative Review
}

Young Il Won, Woon Tak Yuh, Shin Won Kwon, Chi Heon Kim, Seung Heon Yang, Kyoung-Tae Kim and Chun Kee Chung

Int J Spine Surg 2021, 15 (suppl 3) S47-S53

doi: https://doi.org/10.14444/8163

http://ijssurgery.com/content/15/suppl_3/S47

This information is current as of April 26, 2023.

Email Alerts Receive free email-alerts when new articles cite this article. Sign up at:

http://ijssurgery.com/alerts

The International Journal of Spine Surgery

2397 Waterbury Circle, Suite 1,

Aurora, IL 60504, Phone: +1-630-375-1432

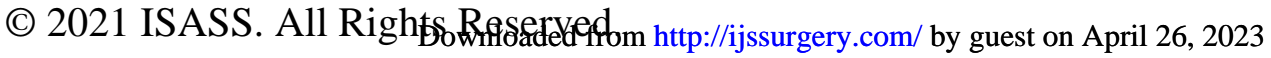




\title{
Interlaminar Endoscopic Lumbar Discectomy: A Narrative Review
}

\author{
YOUNG IL WON, MD ${ }^{1}$; WOON TAK YUH, MD ${ }^{1}$; SHIN WON KWON, MD ${ }^{1}$; CHI HEON KIM, MD, PHD ${ }^{1,2}$; \\ SEUNG HEON YANG, MD ${ }^{1}$; KYOUNG-TAE KIM, MD, PHD ${ }^{3,4}$; AND CHUN KEE CHUNG, MD, PHD ${ }^{1,2,5}$ \\ ${ }^{1}$ Department of Neurosurgery, Seoul National University Hospital, Seoul, Republic of Korea; ${ }^{2}$ Department of Neurosurgery, Seoul National University College of \\ Medicine, Seoul, Republic of Korea; ${ }^{3}$ Department of Neurosurgery, Kyungpook National University Hospital, South Korea; ${ }^{4}$ Department of Neurosurgery, School of \\ Medicine, Kyungpook National University, South Korea; ${ }^{5}$ Department of Brain and Cognitive Sciences, Seoul National University, Seoul, Republic of Korea
}

\begin{abstract}
Background: When pain caused by lumbar disc herniation (LDH) is not relieved after 4 to 6 weeks of conservative treatment, surgery is recommended. Open microdiscectomy is a standard surgical technique, but surgical endoscopy enables endoscopic lumbar surgery with clinical outcomes similar to those of standard microdiscectomy. Endoscopic lumbar discectomy is largely divided into transforaminal endoscopic lumbar discectomy (TELD) and interlaminar endoscopic lumbar discectomy (IELD). TELD was introduced about 10 years earlier than IELD and seems to be more popular than IELD.

Objective: The present article reviews the surgical technique, indications, and outcomes of IELD. Although much is still unknown, potential future perspectives are reviewed.

Summary: Although improved surgical techniques enable TELD to be versatile, IELD is still specifically beneficial for patients with highly migrated LDH and a high iliac crest. There is a large body of literature indicating favorable outcomes with both TELD and IELD. Currently, the selection of TELD or IELD is at the discretion of the surgeon, but the IELD surgical technique is useful for further applying endoscopic lumbar surgery for lumbar decompression or lumbar interbody fusion. The techniques can be assisted by advanced technologies such as artificial intelligence, surgical robots, and artificial reality, and a precise and systematic approach to decision-making and surgical techniques is required to combine these technologies effectively.
\end{abstract}

Special Issue

Keywords: spine, discectomy, lumbar vertebra, endoscopic surgery, review

\section{INTRODUCTION}

When patients suffer intractable pain due to lumbar disc herniation $(\mathrm{LDH})$, conservative treatment, such as rest, light exercise, physical therapy, medication, and epidural injections, is effective; however, approximately $10 \%$ of patients cannot obtain relief, and surgery is recommended. Usually, open discectomy is a standard surgical procedure of choice, but an injury to innocent structures is concerning, and the concern has led physicians to develop a new surgical technique. Endoscopic visualization enables spine surgeons to transition from open surgery to minimally invasive techniques, including full-endoscopic spinal surgery. ${ }^{1-3}$

Since the introduction of spinal endoscopic surgery 30 years ago, both techniques and instruments have been evolving together. ${ }^{2}$ When it was first introduced, the neutral foramen approach was the only approach. ${ }^{2-4}$ Although the standard surgical technique used the interlaminar window, the idea of approaching the spinal canal with a spinal endoscope through an interlaminar window was introduced about 10 years after the transforaminal approach. ${ }^{5,6}$ Although there are many variations of the approach, most fall into one of two categories: transforaminal endoscopic lumbar discectomy (TELD) and interlaminar endoscopic lumbar discectomy (IELD) ${ }^{7,8}$ The present review article uses official TELD and IELD nomenclature. ${ }^{7}$

IELD is utilized for two purposes. First, IELD is a complementary surgical technique to TELD. The use of TELD alone in situations such as highly migrated disc herniation or large disc herniation may put patients at risk of neural injury or incomplete surgery, ${ }^{9,10}$ but these challenges can be addressed using IELD..$^{5,11-13}$ Second, advanced techniques, such as endoscopic decompression or fusion surgeries, use the interlaminar route. ${ }^{14-17}$ In this regard, TELD and IELD are complementary surgical techniques for lumbar herniated discs and may be necessary skills for spinal endoscopic surgeons. ${ }^{13}$ The present article will review IELD in terms of indications, surgical techniques, clinical outcomes, and future perspectives.

\section{INDICATIONS}

Any kind of symptomatic LDH that is medically intractable for more than 4 weeks can be addressed by 
either TELD or IELD. However, IELD may be preferred in specific situations; IELD is efficacious when the iliac crest blocks the transforaminal route, the segmental artery runs at the lower half of the neural foramen, the herniated disc is highly migrated, or the herniated disc occupies more than $50 \%$ of the spinal canal, because it is difficult to completely remove LDH by TELD alone. ${ }^{11,12,17-21}$ At the L5-S1 level, the selection of surgical approach depends upon the location of disc herniation. TELD is preferred for disc herniation located at the center of the disc or shoulder of the nerve root, and IELD is particularly useful for migrated disc herniation. ${ }^{19}$ However, the aforementioned shortcomings of TELD could be overcome by using a transiliac approach and foraminoplasty. ${ }^{22-24}$ Chen et al published a systematic review in which the surgical outcomes were the same for TELD and IELD, except for a high risk of dural injury in IELD. ${ }^{25}$ Another systematic review revealed that recurrent disc herniation was not dependent on surgical techniques (ie, TELD vs IELD) but was associated with older age, obesity, upper lumbar disc, and central disc herniation. ${ }^{26}$ Currently, the selection of TELD or IELD is at the discretion of surgeons. For L5-S1 level disc herniation, the selection is dependent upon the surgical experience of each surgeon. ${ }^{6,13,22,24-26}$ TELD may be preferred for upper lumbar levels due to the narrower laminar and larger thecal sac compared to lower lumbar levels, namely, L3-4 or L4-5. The specific indication for IELD can be summarized as follows:

- A large LDH that occupies more than $50 \%$ of the spinal canal at any spinal level

- A highly migrated LDH at any spinal level

- A complicated case for TELD due to a high riding iliac crest or low-lying segmental vessel at the neural foramen

- A migrated LDH at the L5-S1 level

\section{IMAGING STUDIES}

Using recent magnetic resonance imaging (MRI), the location of the LDH relative to the nerve root should be carefully observed to determine whether to use the shoulder or axillar approach for discectomy. ${ }^{27}$ The shoulder approach is selected when the LDH locates to the lateral side of the nerve root or is superiorly migrated, while the axillary approach is selected when the LDH locates to the medial side of the nerve root, is inferiorly migrated, or occupies more than $50 \%$ of the spinal canal..$^{27} \mathrm{~A}$ computed tomography scan is required to observe the calcification of the disc, identify the location of the iliac crest, and simulate the trajectory of the approach. A plain x-ray image is also helpful in obtaining a full picture of spinal curvature. ${ }^{28}$

\section{SURGICAL PROCEDURE}

IELD is performed with the patient in the prone position under local, epidural, or general anesthesia. After positioning the patient on the surgical table, an intraoperative fluoroscope is used to localize the surgical level, with the surgeon standing on the symptomatic side. The surgery proceeds in the following order:

1. After identifying the surgical level, an 8- to $10-\mathrm{mm}$ skin incision is made above the center of the ipsilateral interlaminar window under intraoperative fluoroscopic guidance.

2. The thoracolumbar fascia is incised with a No. 10 scalpel (Figure 1A). The incision corresponds to the location of the nerve root, and the surgeon should be careful not to penetrate the ligamentum flavum (LF) with a scalpel to prevent inadvertent injury to the dura or nerve root.

3. A dilator is inserted through the incision and laterally advanced until it touches the facet joint. After touching the facet joint, the anteriorposterior and lateral radiographs are used to locate the tip of the dilator. The multifidus muscle is blindly dissected with the dilator from the cranial and caudal lamina. The trajectory of the approach is not vertical to the spinal canal but oblique to the base of the medial facet joint to reach the lateral margin of the nerve root (Figure 1B).

4. After dissecting the multifidus muscle with the dilator, a beveled-type working tube is inserted along the dilator with the open side of the working tube facing the medial side. The endoscope is introduced through the working tube.

5. With endoscopic visualization, the border between the capsule of the facet joint and the LF is identified by color, palpation, and coagulation. The border is incised with endoscopic scissors, and the working tube is advanced along the medial border of the facet joint. Because of the angle of the facet joint and the relative location of the nerve root below, the surgical trajectory of the working tube and endoscope are medially tilted, and the LF is detached from the medial facet joint using a dissector and the blade of the working tube (Figure 1B). 


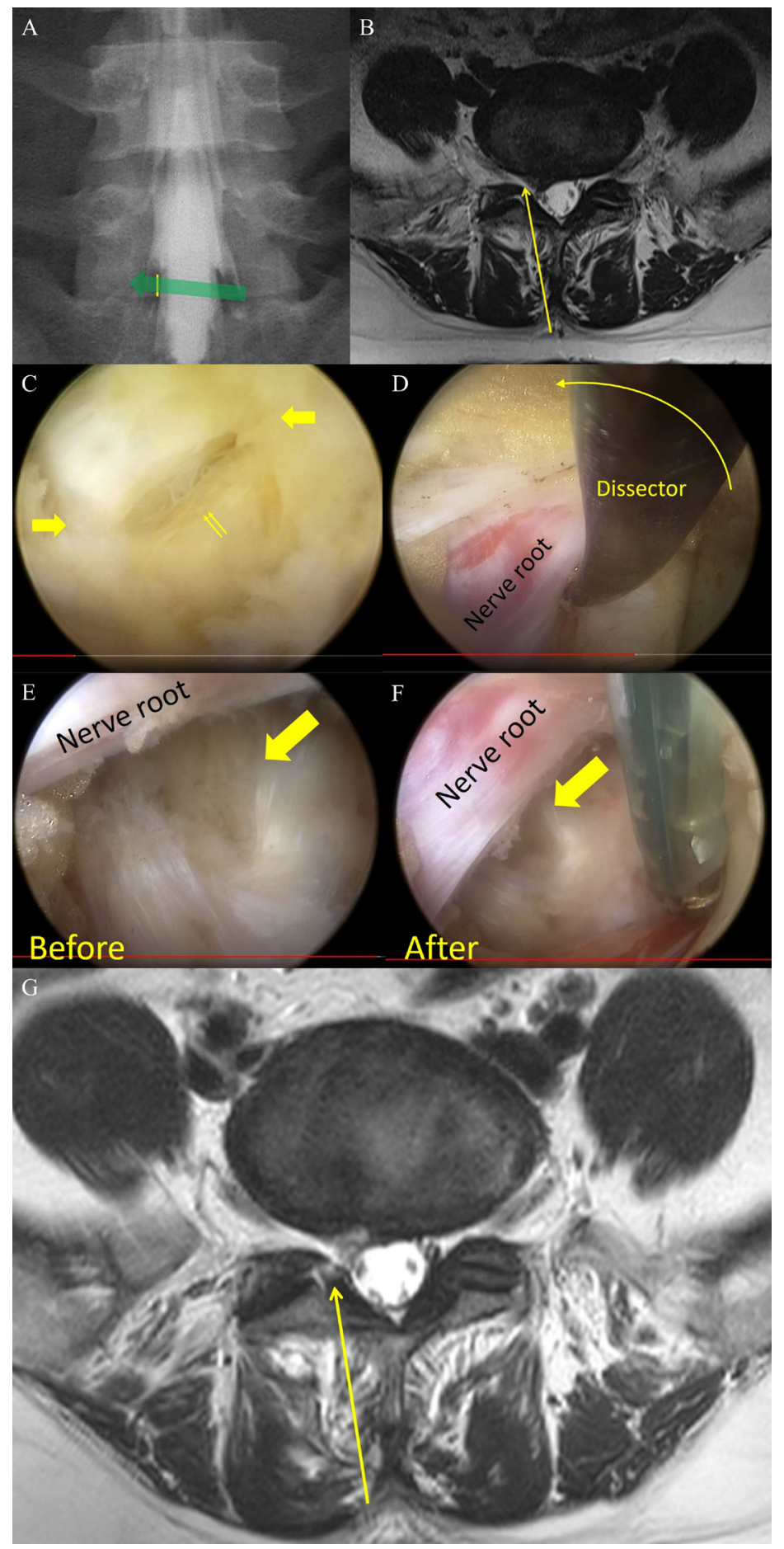

Figure 1. Surgical techniques. (A) Skin incision. The skin incision (yellow line) is overlaid on the spinal myelogram to better understand the surgical trajectory. Usually, transversing nerve roots passing below the lateral margin of the interlaminar window and straight trajectories are associated with a risk of nerve root injury. (B) Preoperative magnetic resonance image and surgical trajectory. The surgical trajectory was oriented obliquely lateral, and the dilator, working tube, and endoscope were medially inclined for the trajectory until opening of the ligamentum flavum and identification of the nerve root. (C) Opening of ligamentum flavum. The outer layer of the ligamentum flavum is incised with scissors (thick arrow), and the inner layer is carefully opened with scissors (double arrow). (D) Rotation of the working tube and retraction of the nerve root. After dissecting the lateral border of the nerve root, the dissector was placed under the nerve root, and the working tube was gently rotated. The dissector was used to put the nerve root away from the blade of the working tube while rotating the working tube. (E, F) Sealing of the annular defect. After removal of the ruptured disc and loose fragments, the defect at the annulus (arrow) is narrowed by coagulating the annulus while pushing the annulus to the side of the defect. (G) Postoperative magnetic resonance imaging. Postoperative T2-weighted axial magnetic resonance image showed a defect in the ligamentum flavum and disappearance of the ruptured disc. The yellow arrow indicates the surgical trajectory, and the opening in the ligamentum flavum was shown with a high signal at the end of the yellow arrow. 
6. When the working tube has nearly reached the lateral border of the LF at the lateral recess, the LF is incised with scissors while pushing the working tube down against the LF to maintain tension. First, the outer layer is removed with scissors and is gradually enlarged up to approximately $4 \mathrm{~mm}$ until the inner layer of the LF is exposed (Figure 1C). Usually, the LF turns gray when the outer layer is removed.

7. The remaining inner layer is carefully opened with scissors and is enlarged using scissors or endoscopic Kerrison rongeurs. If the disc herniation is not large, the LF can be preserved by splitting it with a working tube and dissector. ${ }^{27}$

8. After entering the spinal canal, the axilla or shoulder of the nerve root is searched for as preoperatively planned. For the shoulder approach, the lateral border of the nerve root is identified and dissected up and down. The working tube is placed at the lateral border of the nerve root and rotated $180^{\circ}$ to retract and protect the nerve root behind the working tube (Figure 1D).

9. The discectomy is performed through the working tube's safely secured surgical field. For an extruded disc, the weakest spot of the annulus is popped up, and the herniated disc is removed through the hole. If the annulus is not naturally popped up, the weakest point is located and incised with a small endoscopic scalpel; discectomy is done through a small hole. After removal of the ruptured disc material, loose fragments, which sit under the ruptured disc, are removed. ${ }^{10}$ During a discectomy, excessive retraction should not be attempted or performed for a brief time to avoid neural injury, and intermittent release or derotation of the working tube helps prevent neurological complications. If the herniated disc is large (occupying more than $50 \%$ of the spinal canal), partial removal through either the shoulder or axilla of the nerve root before retraction of the nerve root with the working tube is necessary to prevent trauma.

10. After the discectomy, the defect of the annulus can be tightened and reduced in size by careful coagulation of the surrounding annulus (ie, sealing technique) (Figure 1E) ${ }^{29}$

11. After meticulous hemostasis, the whole endoscopic system is removed, and the skin is sutured. If postoperative bleeding is a concern, a closed suction drain is inserted through the working tube after removal of the endoscope, and only the working tube is removed. The enlarged ligamentum is usually reduced in size and leaves a small defect at the LF (Figure 1F).

\section{POSTOPERATIVE COURSE}

Usually, the patient is encouraged to ambulate from the day of surgery and discharged the next day. Outpatient clinics are scheduled at 1, 3, 6, and 12 months and yearly thereafter. Any lumbar support is not recommended as a routine. Gentle exercise is allowed, but hard exercise is limited for approximately 3 months. Returning to work is allowed within 1 month for office jobs and within 3 months for physically active jobs.

\section{CLINICAL OUTCOMES}

There has been no randomized controlled trial that utilized IELD as the sole surgical technique. Ruetten et al published the results of a cohort study using IELD for 331 patients who were followed up with for more than 2 years in $2006 .{ }^{5}$ The result was encouraging, with $95 \%$ of patients experiencing no pain or only occasional pain and recurrence in $2.4 \%$ of patients. ${ }^{5}$ In 2006, Choi et al published a surgical technique for IELD using a serial dilator to make an opening at the LF. ${ }^{6}$ A favorable outcome was achieved in $91 \%$ of patients, with a recurrence rate of $1.4 \% .^{6}$ Choi et al specifically applied IELD for L5-S1 level cases, but Ruetten et al used IELD across various spinal levels. ${ }^{5,6}$ In an overall systematic review, surgical outcomes did not differ between TELD and IELD, except for the higher occurrence of dural injury after IELD $(P=.04)$ than after TELD. ${ }^{25}$ What matters is not the endoscopic trajectory but the use of endoscopy in lumbar discectomy. ${ }^{13}$ The randomized controlled trial by Ruetten et al showed that favorable clinical outcomes (no pain or occasional pain) were achieved in $96 \%$ of patients after either endoscopic surgery (TELD or IELD) or a standard microdiscectomy, with a recurrence rate of $6.2 \%$ in both groups. ${ }^{13}$ These results inspired further use of fully endoscopic surgery for LDH. Because the endoscope passes through the paraspinal muscle, there is a concern of muscle injury after IELD. Choi et al analyzed biomarkers of muscle injury (creatine phosphokinase) after surgery and found higher levels after open discectomy than after TELD or IELD. ${ }^{30}$ There was no significant difference in levels between TELD and IELD. ${ }^{30}$ A recent systematic review comparing full-endoscopic lumbar discectomy and microdiscectomy showed that postoperative 
pain, disability index, complication rate, and recurrence rate were not significantly different between the techniques. ${ }^{31}$ Advantages of endoscopic lumbar discectomy were a short operation time and hospital stay. ${ }^{31}$

\section{CASE}

A 40-year-old woman visited the clinic having had a medically intractable LDH on her right leg and back for 6 months. Although surgical treatment had been recommended 3 months prior after failed nonsurgical treatment, including epidural injection, she did not want surgical treatment and endured with medication and repeated epidural injections and epidural neurolysis. When she visited the outpatient clinic, she showed an antalgic gait and was restless with pain (numerical rating score of pain was $8 / 10$ ). Her Oswestry Disability Index score was 32 out of 50. MRI revealed a protruded LDH at the L5-S1 level (Figure 2A and B). Because she preferred a minimally invasive surgery, IELD was performed under general anesthesia. The pain was almost gone just after surgery (numerical rating score was $2 / 10$ ), and she could walk normally on the day of the surgery. Postoperative MRI showed removal of the herniated disc (Figure 2C and D). She went home the day after surgery and returned to normal life 2 weeks later.

\section{FUTURE PERSPECTIVES}

Recent developments in surgical robotic systems, artificial reality, and artificial intelligence (AI) are eyeopening. ${ }^{32-35}$ To date, doctors have been responsible for surgical decisions and surgery, but the outcomes are heterogeneous, probably due to diverse decision-making processes and surgical expertise. ${ }^{6,13,22,24-26}$ The expectation for $\mathrm{AI}$ and robotic systems is precision medicine, and with the development of new technology, decisionmaking and surgical procedures could be replaced by $\mathrm{AI}$ and robots in the near future. ${ }^{33-35}$ We cannot stop evolution, but we can work toward systematic, reproducible, reliable, and precise surgical decisions and skills with $\mathrm{AI}$ and robotics.

\section{CONCLUSION}

IELD is a surgical technique for full-endoscopic lumbar discectomy, along with TELD. The surgical outcomes for IELD reported in the literature were not different from those of TELD, but outcomes can only be guaranteed by keeping strictly to surgical indications and correct surgical techniques. New technologies are continuously being developed, and precise/systematic judgment and surgical skills are required now more than ever.

\section{REFERENCES}

1. Ruetten S, Meyer O, Godolias G. Endoscopic surgery of the lumbar epidural space (epiduroscopy): results of therapeutic intervention in 93 patients. Minim Invasive Neurosurg. 2003;46(1):1-4. doi:10.1055/s-2003-37962.

2. Kambin P. Arthroscopic microdiscectomy. Arthroscopy. 1992;8(3):287-295. doi:10.1016/0749-8063(92)90058-j.

3. Yeung AT, Yeung CA. Advances in endoscopic disc and spine surgery: foraminal approach. Surg Technol Int. 2003;11:255-263.

4. Hermantin FU, Peters T, Quartararo L, Kambin P. A prospective, randomized study comparing the results of open discectomy with those of video-assisted arthroscopic microdiscectomy. $J$ Bone Joint Surg Am. 1999;81(7):958-965. doi:10.2106/00004623199907000-00008.

5. Ruetten S, Komp M, Godolias G. A New full-endoscopic technique for the interlaminar operation of lumbar disc herniations using 6-mm endoscopes: prospective 2-year results of 331 patients. Minim Invasive Neurosurg. 2006;49(2):80-87. doi:10.1055/s-2006-932172.

6. Choi G, Lee S-. H, Raiturker PP, Lee S, Chae Y-. S. Percutaneous endoscopic interlaminar discectomy for intracanalicular disc herniations at L5-S1 using a rigid working channel endoscope. Neurosurgery. 2006;58(1 Suppl):S59-68. doi:10.1227/01.neu. 0000192713.95921.4a.

7. Hofstetter CP, Ahn Y, Choi G, et al. AOSpine consensus paper on nomenclature for working-channel endoscopic spinal procedures. Global Spine J. 2020;10(2 Suppl):111S-121S doi:10.1177/2192568219887364.

8. Fujita M, Kawano H, Kitagawa T, et al. Preoperative design for the posterolateral approach in full-endoscopic spine surgery for the treatment of L5/S1 lumbar disc herniation. Neurospine. 2019;16(1):105-112. doi:10.14245/ns.1836316.158.

9. Baek J, Yang SH, Kim $\mathrm{CH}$, et al. Postoperative longitudinal outcomes in patients with residual disc fragments after percutaneous endoscopic lumbar discectomy. Pain Physician. 2018;21(4):30045612):E457-E466:. doi:10.36076/ ppj.2018.4.E457.

10. Heo JH, Kim CH, Chung CK, et al. Quantity of disc removal and radiological outcomes of percutaneous endoscopic lumbar discectomy. Pain Physician. 2017;20(5):E737-E746.

11. Kim CH, Chung CK, Woo JW. Surgical outcome of percutaneous endoscopic interlaminar lumbar discectomy for highly migrated disk herniation. Clin Spine Surg. 2016;29(5):E259-66. doi:10.1097/BSD.0b013e31827649ea.

12. Kim CH, Chung CK, Jahng T-A, Yang H-J, Son Y-J. Surgical outcome of percutaneous endoscopic interlaminar lumbar diskectomy for recurrent disk herniation after open diskectomy. J Spinal Disord Tech. 2012;25(5):E125-33. doi:10.1097/ BSD.0b013e31825bd111.

13. Ruetten S, Komp M, Merk H, Godolias G. Full-endoscopic interlaminar and transforaminal lumbar discectomy versus conventional microsurgical technique: a prospective, randomized, controlled study. Spine. 2008;33(9):931-939. doi:10.1097/ BRS.0b013e31816c8af7.

14. Komp M, Hahn P, Oezdemir S, et al. Bilateral spinal decompression of lumbar central stenosis with the full-endoscopic 


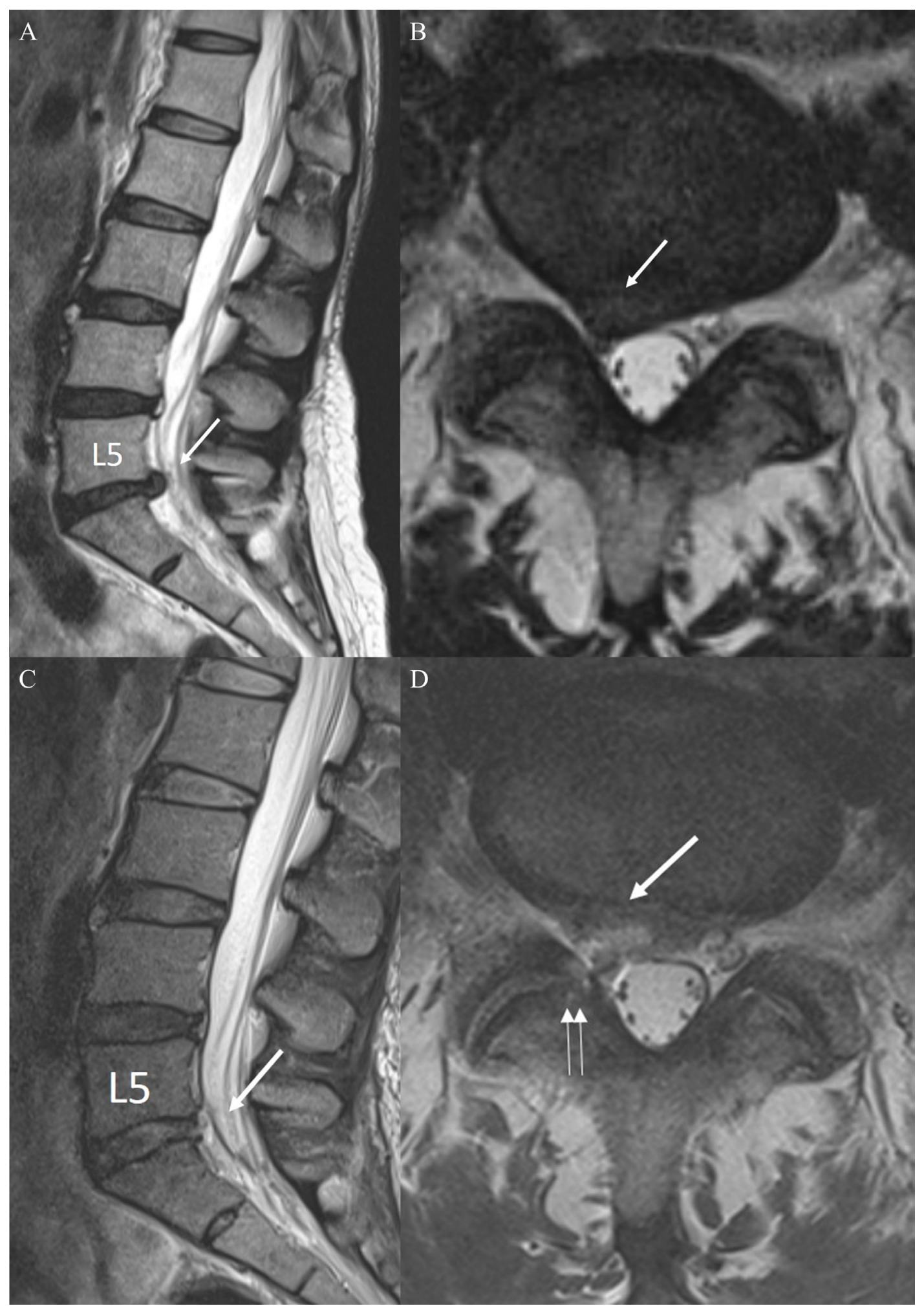

Figure 2. Case. Preoperative T2-weighted magnetic resonance images of a sagittal cut (A) and an axial cut (B) showed a protruded disc (white arrow). Postoperative magnetic resonance images $(C$ and $D)$ showed a sufficiently decompressed nerve root after removal of the herniated disc (white arrow) and a defect of the ligamentum flavum (double white arrows).

interlaminar versus microsurgical laminotomy technique: a prospective, randomized, controlled study. Pain Physician. 2015;18(1):61-70. doi:10.36076/ppj/2015.18.61.
15. Birkenmaier C, Komp M, Leu HF, Wegener B, Ruetten S. The current state of endoscopic disc surgery: review of controlled studies comparing full endoscopic procedures for disc herniations 
to standard procedures. Pain Phys. 2013:335-344. doi:10.36076/ ppj.2013/16/335.

16. Ito F, Ito Z, Shibayama M, et al. Step-by-step sublaminar approach with a newly-designed spinal endoscope for unilateralapproach bilateral decompression in spinal stenosis. Neurospine. 2019;16(1):41-51. doi:10.14245/ns.1836320.160.

17. Khandge AV, Kim J-S. Modified interlaminar endoscopic lumbar discectomy for highly upmigrated disc herniation: a proctorship description of the technique via translaminar route. Neurospine. 2020;17(Suppl 1):S66-S73. doi:10.14245/ns.2040264.132.

18. Choi K-. C, Lee DC, Shim H-. K, Shin S-. H, Park C-. K. A strategy of percutaneous endoscopic lumbar discectomy for migrated disc herniation. World Neurosurg. 2017;99:259-266. doi:10.1016/j.wneu.2016.12.052.

19. Choi KC, Kim J-. S, Ryu K-. S, Kang BU, Ahn Y, Lee S-. H. Percutaneous endoscopic lumbar discectomy for L5-S1 disc herniation: transforaminal versus interlaminar approach. Pain Physician. 2013;16(6):547-556. doi:10.36076/ppj.2013/16/547.

20. Choi K-C, Lee J-H, Kim J-S, et al. Unsuccessful percutaneous endoscopic lumbar discectomy: a single-center experience of 10,228 cases. Neurosurgery. 2015;76(4):372-380. doi:10.1227/ NEU.0000000000000628.

21. Lee S, Kim S-K, Lee S-H, et al. Percutaneous endoscopic lumbar discectomy for migrated disc herniation: classification of disc migration and surgical approaches. Eur Spine J. 2007;16(3):431-437. doi:10.1007/s00586-006-0219-4.

22. Choi G, Lee S-. H, Lokhande P, et al. Percutaneous endoscopic approach for highly migrated intracanal disc herniations by foraminoplastic technique using rigid working channel endoscope. Spine. 2008;33(15):E508-15. doi:10.1097/BRS.0b013e31817bfa1a.

23. Lee S-. H, Kang HS, Choi G, et al. Foraminoplastic ventral epidural approach for removal of extruded herniated fragment at the L5-S1 level. Neurol Med Chir. 2010;50(12):1074-1078. doi:10.2176/nmc.50.1074.

24. Choi G, Kim J-. S, Lokhande P, Lee S-. H. Percutaneous endoscopic lumbar discectomy by transiliac approach: a case report. Spine. 2009;34(12):E443-6. doi:10.1097/BRS.0b013e31817c4f39.

25. Chen J, Jing X, Li C, Jiang Y, Cheng S, Ma J. Percutaneous endoscopic lumbar discectomy for $15 \mathrm{~s} 1$ lumbar disc herniation using a transforaminal approach versus an interlaminar approach: a systematic review and meta-analysis. World Neurosurg. 2018;116:412-420. doi:10.1016/j.wneu.2018.05.075.

26. Yin S, Du H, Yang W, Duan C, Feng C, Tao H. Prevalence of recurrent herniation following percutaneous endoscopic lumbar discectomy: a meta-analysis. Pain Physician. 2018;21(4):337-350. doi:10.36076/ppj.2018.4.337.

27. Kim $\mathrm{CH}$, Chung $\mathrm{CK}$. Endoscopic interlaminar lumbar discectomy with splitting of the ligament flavum under visual control. J Spinal Disord Tech. 2012;25(4):210-217. doi:10.1097/ BSD.0b013e3182159690.

28. Kim R, Kim $\mathrm{RH}, \mathrm{Kim} \mathrm{CH}$, et al. The incidence and risk factors for lumbar or sciatic scoliosis in lumbar disc herniation and the outcomes after percutaneous endoscopic discectomy. Pain Physician. 2015;18(6):555-564. doi:10.36076/ppj.2015/18/555.
29. Lee J-S, Kim H-S, Jang J-S, Jang I-T. Structural preservation percutaneous endoscopic lumbar interlaminar discectomy for 15-s1 herniated nucleus pulposus. Biomed Res Int. 2016;2016:6250247. doi:10.1155/2016/6250247.

30. Choi K-. C, Shim H-. K, Hwang J-. S, et al. Comparison of surgical invasiveness between microdiscectomy and 3 different endoscopic discectomy techniques for lumbar disc herniation. World Neurosurg. 2018;116:e750-e758. doi:10.1016/j.wneu.2018.05.085.

31. Ruan W, Feng F, Liu Z, Xie J, Cai L, Ping A. Comparison of percutaneous endoscopic lumbar discectomy versus open lumbar microdiscectomy for lumbar disc herniation: a meta-analysis. Int $J$ Surg. 2016;31:86-92. doi:10.1016/j.ijsu.2016.05.061.

32. Katsuura Y, Colón LF, Perez AA, Albert TJ, Qureshi SA. A primer on the use of artificial intelligence in spine surgery. Clin Spine Surg. 2021;34(9):316-321. doi:10.1097/BSD.0000000000001211.

33. Joshi RS, Lau D, Ames CP. Artificial intelligence for adult spinal deformity: current state and future directions. Spine $J$. 2021;21(10):1626. doi:10.1016/j.spinee.2021.04.019.

34. Ghaednia H, Fourman MS, Lans A, et al. Augmented and virtual reality in spine surgery, current applications and future potentials. Spine J. 2021;21(10):1617-1625. doi:10.1016/j. spinee.2021.03.018.

35. Wirries A, Geiger F, Hammad A, Oberkircher L, Blümcke I, Jabari S. Artificial intelligence facilitates decisionmaking in the treatment of lumbar disc herniations. Eur Spine J. 2021;30(8):2176-2184. doi:10.1007/s00586-020-06613-2.

Funding: This work was supported by the New Faculty Startup Fund from Seoul National University.

Declaration of Conflicting Interests: The corresponding author (C.H.K.) is a consultant of RIWOspine GmbH. All other authors declare that they have no conflicts of interest concerning the materials/ methods used in this study or the findings described in this article. No benefits in any form have been or will be received from any commercial party related directly or indirectly to the subject of this manuscript.

Corresponding Author: Chi Heon Kim, MD, $\mathrm{PhD}$, Department of Neurosurgery, Seoul National University College of Medicine, 101 Daehak ro, Jongno-gu, Seoul, 110-744, Republic of Korea; Phone: +822-2072-3398; Fax: +82-2-744-8459; chiheon1@ @nu.ac. $\mathrm{kr}$.

Published 27 December 2021

This manuscript is generously published free of charge by ISASS, the International Society for the Advancement of Spine Surgery. Copyright @) 2021 ISASS. To see more or order reprints or permissions, see http:// ijssurgery.com. 